\title{
LITERATURA “MENOR": Linguagem e Identidade Cultural num Conto Afro-Americano
}

Regina M. Przybycien ${ }^{\star}$

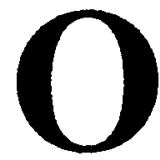

conto "Just don't never give up on love" de Sonia Sanchez' foi escollido para o curso "O conto dos anos oitenta ${ }^{{ }^{2}}$ por representar uma importante corrente da produção literária norte-americana contemporânea: a literatura das minorias étnicas. A escollha de um conto afro-americano se deve sobretudo ao fato de que, já há várias décadas, os escritores negros norte-americanos vêm produzindo uma literatura distinta, representativa de sua própria cultura, de valor internacionalmente reconhecido. Além disso, ao contrário da produção literária da maioria das outras etuias, a distinção não é meramente temática. Os escritores afro-americanos criaram uma linguagem literária inspirada na fala dos guetos e das pequenas comunidades rurais do Sul dos Estados Unidos onde a etnia negra predomina. Ao mesmo tempo, absorveram o ritmo do jazz $\mathrm{e}$ do blues, criando uma musicalidade própria, que se manifesta nas variações poéticas das frases.

* Universidade Federal do Paraná.

I SANCHEZ, Sonia. Just don it never give up on love. Parmassis: poetry in review. Spring/Summer/Fall/Winter, 1985, p.353-56.

2 Curso de Extensĩo: O conto dos anos oitenta. UFPR, 26 a 30 de setembro de 1994. 
A literatura afro-americana pode ser classificada, utilizando-se a terminologia de Deleuze e Guattari, como "literatura menor". Esta, entretanto, não deve ser entendida como menos importante ou de inenor valor estético, mas como uma manifestação literária que subverte a lingua olicial. ${ }^{3}$

Deleuze e Guattari analisam especificamente a situação de Kafka: judeu, nascido na República Tcheca, falante nativo de três línguas (o alemão, o ídiche c o tcheco), Kalka escolheu escrever em alemão, não o alemão literário.tradicional, mas aquele utilizado pela pequena comunidade intelectual de Praga, cultura marginal situada ao mesmo tempo dentro e fora da tradição germânica.

Também os negros norte-americanos produzem "literatura menor" no sentido aqui descrito. Preocupados em criar a sua própria identidade cultural, consideram a língua padrão, instrumento de dominação imposto pelo senhor ao escravo, inadequada como meio de expressão. Já na década de trinta o escritor Richard Wright utilizava o dialeto dos guetos na sua lïção naturalista. $O$ poeta Langston Hughes, por sua vez, incorporava o rimo do jazz e dos blues, inaugurando uma poesia de expressão negra diferente da tradição anglo-americana tradicional. Essa tendencia só aumentou a partir da década de sessenta. A luta pelos dircitos civis, com suas conquistas e recuos, fez crescer a convicção de que a língua, a cultura e, por conseguinte, a literatura oliciais não representam os negros.

A literatura afro-americana recria, portanto, o Black English (dialeto rejeitado pela cultural oficial como signo da ignorância e subdesenvolvimento do negro) e laz dele a sua língua literária. Realiza, portanto, uma luta de guerrilha à língua olicial, introduzindo nela, nas palavras de Deleuze e Guattari, "seu próprio patoá, seu próprio terceiro mundo, seu próprio descrto."

É necessário ter em mente, entretanto, que é impossivel um rompinento radical com a tradição da "grande" literatura. Os escritores afro-americanos se situam num entre-lugar ambiguo e sempre precairio entre a opção deliberada pela representação do dialcto e da cultura do negro e a sua fonnação intelectual dentro da tradição ocidental. O resultado, como não poderia deixar de ser, revela-se paradoxal. Freqüentemente pode-se reconhecer naquilo que se pretende marcar com o signo da diferença um intertexto familiar, a marea da semelhança, como por exemplo, personagens que falam como negros mas em torno dos quais se delineiam grandes temas da literatura ocidental: o parricídio edipiano, a dúvida hamletiana, os sonhos quixolescos, c tantos outros.

3 DELEUZE, Gilles; GUATTARI, Felix. Kafka: por uma literatura menor. Trad. Júlio Castanon Guimaries. Rio de Janciro : Imaigo, 1977, p.25.

4 Ibid., p.28. 
Julgo necessário iniciar a discussāo do conto escolhido pelo que apresenta de mais caracteristico: a linguagem. A autora, Sonia Sanchez, é poeta. Mais do que contos, escreve longos poemas em prosa, ou o que Herbert Leibowitz chamou de vinhetas poćticas, das quais "Just don't never give up on love" é das mais representativas. 5

Nessa história extremamente curta e quase sem ação, bascada num fato verídico (a conversa, num banco de parque, entre a autora e uma senhora de noventa c quatro anos), a fala da personagem é um dos elementos mais importantes. Ela marca o contraste entre a personagem e a narradora e delimita o fosso social que as separa. A vella scuhora, personagem do conto, revela, pela linguagem, o universo do gueto, suas estruturas sociais machistas, a condição marginal da mulher negra mas tambím (e principalmentc) a sua força $e$ a sua poesia, porque a fala é extremamente pótica.

Sonia Sanchez declarou: "Minha poesia aborda o significado de ser mulher também de forma irônica, retratando mulheres que foran violadas como a terra loi violada. Tento enfocar as injustiças e os erros de mancira ao mesıno tempo incisiva e amorosa." ${ }^{\circ 6}$ É a poesia na voz da personagem que da grandeza à história banal de amores e traiçōes.

A narradora, por sua vez, é caracterizada como intelectual, escritora, aquela que, por profissão, domina a linguagem. Ela é a mulher negra de classe média, preocupada com o trabalho intelcctual e com a criação dos fillhos. Sua atitude inicial é ignorar a velha senhora, simbolo de um mundo que quer esquecer: a identidade negra, o apelo éunico, o gueto. Scu sentimento de rejeição aparece de mancira forte no texto em inglès, quando reage à intromissāo da mulher com o pensamento: "Hell. No rap from the roots today", que pode ser traduzido aproximadamente por: -Droga, sem cobrança das origens hoje."

Um dos sentidos de rapé conversa, mas a palavra pode significar também censura. A narradora não quer se sentir cobrada por viver o presente e ignorar as raizes, a identidade étnica, por estar inserida no mundo dos brancos, falando e escrevendo como eles.

A tradução do conto para o português, feita por mim para o curso mencionado no início deste artigo, merece uma rellexão pelas peculiaridades da linguagem da personagem. Apesar de bastante curto, o conto apresenta dificul-

5 LEIBOWITZ, Herbert. Exploding myths: an interview with Sonia Sanchez. Parnassiss. Spring/Summe/Fall/Winter, 1985, p.361.

6 My poetry has talked about what it means to be a woman ironically, too, in portraits of women who have been violated, as the earth has been violated. I try to fixus altention on injustices, on wrongs, but I try to do it in a way that is both sharp and loving. LEIBOWITZ, p.357.

(As traduçòes para o portuguis dos textos de Sonia Sanchez foram feitas pela autora deste artigo).

7 SANCHEZ, Sonia. Just don't never give up on love, p. 353. 
dades intransponíveis, já que é impossivel reproduzir o dialeto negro norte-americano em outras línguas. Foi necessário, portanto, encontrar equivalências que dessem conta da diferença da linguagem da personagem e da narradora. Traduzir a fala da anciã negra para o portugués padrão esvaziaria o conto de sua substância mais rica. Assim, optei por criar um simulacro: uma representação do falar mineiro, mais familiar ao meu ouvido do que outras falas regionais. Tal procedimento, naturalmente, cria outra realidade ficcional. A velha "mineira" do conto em português já não é a mesina personagem do original, pois o seu modo de falar traz conotações diferentes e remete a outro universo, outra ideologia. Esse é o paradoxo de toda tradução.

Eın termos de sua estrutura, o conto ć pouco complexo. Eu o chamaria de conto pós-moderno, por várias razões. Uma delas é a indistinção da fronteira cntre poesia e prosa. Trata-se, comojá foi mencionado, de prosa poética. Embora a história tenha contomos realistas (uma conversa no parque), não há comprometimento com a verossimilhança, isto $\dot{e}$, não se pretende representar o "real". O relato da velha senhora, difuso e fragmentado, não se funda num discurso lógico, mas reproduz, em flashes de imagens, as oscilações da memória.

O enredo também é simples. A narradora, intelectual, escritora, vai ao parque com os fillhos. Não quer ser perturbada, pois tem uma resenha para escrever. Por isso, aborrece-a a presença de uma vella sentada no banco. Senta-se o mais longe possivel dela e volta-lhe as costas. A abordagem nada convencional da anciã causa-lhe espanto, estranheza. Ela funciona um pouco como no teatro do absurdo, onde as convenções de comunicação são subvertidas. A história lembra ligeiramente a peça Zoo Story de Edward Albee, que também se passa num banco de parque. Nela um dos personagens lê um livro e irrita-se com a insistência do outro personagem de romper o silèncio e imiscuir-se na sua privacidade. Na peça o diálogo toma-se delirante, esquisofrênico, conduzindo o leitor (ou espectador) por labirintos insuspeitados de tensão e estranhamento. $O$ conto possui atmosfera bem mais amena.

A abordagem da anciā representa uma intromissão indescjada mas seu eleito é sacudir a narradora, penetrar fundo em coisas reprimidas como amor $\mathrm{e}$ sexo mas também, e sobretudo, chamar a atenção para a condição de ser mulher e ser negra, dupla marginalização que a história problematiza. A mulher, dividida entre sua condição de objeto do desejo e a angústia de não ser mais desejada, leva uma existência periférica, na qual o centro é o outro, o masculino. A narradora tenta se esquivar dessa condição pela evasão. Ȧ pergunta da velha, "Já amô home bunito, moça?" responde com ironia, "Não senhora. Já vi muitos 
homens bonitos. Mas não gosto deles porque mantêm o amor no alto do armário c cu sou muito baixa para alcançá-lo."

O relato da velha senhora é uma afirmação da vida e, como tal, torna a história altamente positiva. Ele sugere que apesar de tudo vale a pena viver intensamente. Da mesma forma que a linguagem constrói a identidade do negro, o tecido da narrativa vai construindo a identidade da mulher: da velhinha alquebrada do inicio da narrativa surge aos poucos o retrato de uma mulher forte que vai tomando forma, ocupando o centro, até atingir. No final apotcótico, quase estatura heróica: "Uma mulher negra. Ecoando ouro. Carregando versos do céu para vincar o chão."9

A interposição da personagem, no início da história, entre a narradora e o livro que necessita resenhar causa, na última, enfado c irritação. Aos poucos, entretanto, ela se rende ao fascínio da fala da personagem e descobre que a verdadeira poesia está nas palavras vivas da mulher negra c não na letra morta do livro. Sua descoberta eria um elo entre as duas mulheres, uma relação de cumplicidade que implica na aceilação, por parte da narradora-poeta, de sua identidade de mulher negra. A narração é também um processo de autodescoberta e de criação de poesia "menor".

Palavras-chave: Literatura Afro-americana, identidade cultural, Sonia Sanchez.

\section{RESUMO}

Este artigo aborda a constituição da literatura afro-americana como literatura "menor", no sentido discutido por Deleuze e Guattari, istoé, aquela que subverte a lingua padrão e a literatura "oficial" de um pais. Tal literatura desempenha importante papel na formação da identidade cultural do negro norte-americano, não só por tratar de temas relativos ao seu mundo, mas, principalmente, por incorporar, na linguagem literária, a fala do gueto e os ritmos da núsica negra, constituindo assim uma tradição literária própria. Tona-se, para análise, o conto "Just don't never give up on love", de Sonia Sanchez, por tratar-se de un belo exemplo de prosa poética, na qual a linguagem colore

8 Has you ever loved a pretty man, girl? ... No ma'am. But I've seen many a pretty man. I don't like them though cuz they keep their love up high in a linen closet and $I^{\prime} \mathrm{m}$ too short to reach it. SANCHEZ, p.354.

9 A black woman. Echoing gold. Carrying couplets from the sky to crease the ground. SANCHEZ, p.356. 
e suaviza temas como a brutalidade e o sofrimento de vidas femininas. $O$ conto é uma atïmação da identidade e uma celebração da força da mulher negra.

\section{ABSTRACT}

This article deals with the question of African-American literature as "minor" literature, in the sense discussed by Deleuze and Guattari; that is, one which subverts the official language and mainstream literature of a country. African-American literature plays an important role in the formation of the African-American cultural identity, not only because it deals with themes related to their ethnic group, but mainly because it incorporated Black English and the rhythms of black music into literature, thus creating its own literary tradition. Sonia Sanchez's short-story "Just don't never give up on love" was chosen for discussion in this paper because it is a beautiful example of AfricanAmerican poetic prose, in which the language colors and softens themes like the brutality and suffering of female lives. The story aftirms the identity and celebrates the strength of the African-American woman.

\section{REFERÊNCIAS BIBLIOGRÁFICAS}

ALBEE, Edward. The American Dream cund Zoo Story: two plays by Edward Albee. New York : Signet Books, 1959.

DELEUZE, Gilles ; GUATTARI, Felix. Kafka: por uma literatura menor. (Trad.) Júlio Castanon Guimarāes. Rio de Janciro : Imago, 1977.

LEIBOWITZ, Herbert. Exploding myths: an interview with Sonia Sanchez. Parnassus: poetry in review. Spring/Summer/Fall/Winter, 1985, p. 357-68.

SANCHEZ, Sonia. Just don't never give up on love. Parnassus: poetry in review. Spring/Summer/Fall/Winter, 1985, p.353-56. 